\title{
Recent Advances In GTR/GBR Barrier Membranes Design for Periodontal Regeneration
}

\author{
Julia Higuchi*1,2, Bartosz Woźniak ${ }^{1}$, Agnieszka Chodara ${ }^{1,2}$, Giuseppino Fortunato $^{3}$ and Witold \\ Łojkowski ${ }^{1}$ \\ ${ }^{1}$ Laboratory of Nanostructures, Institute of High Pressure Physics, Polish Academy of Sciences, Warsaw, Poland \\ ${ }^{2}$ Faculty of Materials Science and Engineering, Warsaw University of Technology, Warsaw, Poland \\ ${ }^{3}$ Swiss Federal Laboratories for Materials Science and Technology (EMPA), St. Gallen, Switzerland
}

*Corresponding author: Julia Higuchi, Laboratory of Nanostructures, Institute of High-Pressure Physics, Polish Academy of

Sciences, Warsaw, Poland

\section{ARTICLE INFO}

Received: 幽 March 05, 2019

Published: March 19, 2019

Citation: Julia Higuchi, Bartosz Woźniak, Agnieszka Chodara, Giuseppino Fortunato, Witold Łojkowski. Recent Advances In GTR/GBR Barrier Membranes Design for Periodontal Regeneration. Biomed J Sci \& Tech Res 16(1)2019. BJSTR. MS.ID.002807.

\author{
ABSTRACT
}

The composite membranes used in dentistry are one of the most popular periodontal regeneration products. They are applied in the procedures where severe periodontium defects need to be reconstructed. The clinical treatment of defects usually consists of surgical intervention and mechanical debridement. Nonetheless, depending on the size of the defected site, the complete regeneration of periodontal tissues remains to be a difficult clinical task. Thus, the use of bioresorbable or non-resorbable barrier membranes employed in guided tissue/bone regeneration (GTR/GBR) procedures have been investigated in terms of their clinical potential in tissue regeneration. Novel experimental findings suggest that membranes should play an active role in promoting the regenerative processes, instead of being purely a passive physical barrier. A variety of biomaterials have been suggested and used so far, most commonly collagen Type I and III, polylactide-PLA, and poly (lactic-co-glycolic acid)-PLGA, which mimic the chemical and physical properties of natural tissues. Synthetic polymers exhibit sufficient mechanical properties and adjustable biodegradation rates.

By controlling their chemical compositions, the membranes can maintain physical integrity for a long period to achieve tissue regeneration. However, polymeric materials are usually hydrophobic in nature and exhibit poor cell affinity. To enhance the properties of synthetic polymer membranes various composite structures have been suggested developed mostly by addition of osteoinductive calcium phosphate ceramics to the polymeric membranes.

\section{Introduction}

Promising procedures for bone reconstruction in dentistry are guided tissue regeneration (GTR) and guided bone regeneration (GBR). Both of these surgical methods involve the restoration of bone deficiencies by means of barrier membranes. GTR implies the regeneration of the bone and attachment anatomical structures (periodontal ligament, cementum) of living teeth, whereas GBR includes the placement of a membrane into the area where the new formation of bone is intended. For either technique, bone or substitute material is used in combination with the membrane $[1,2]$. Barrier membranes are critical for the restoration of the lost tissues. They act as physical separation object, isolating fast growing soft tissues from populating the bone defect site. The coexistence of soft and hard tissue is an anatomical characteristics of the periodontium. Thus, approach considering both bone regeneration and soft tissues separation should be considered when designing new barrier membrane construct [3].

\section{Discussion}

Currently, the membranes for GTR/GBR are engineered to be cell-occlusive, while simultaneously allowing flow of the nutrients 
and other small molecules through the structure. GTR therapy for periodontal defects is currently most popular and accepted as superior to conventional procedures. Non-biodegradable or biodegradable polymer membranes are commercially available for periodontal surgery purposes. Initially, the non-degradable, titanium meshes, expanded polytetrafluoroethylene (e-PTFE) membrane or Gore-Tex ${ }^{\circledR}$, were frequently used for alveolar bone regeneration [4,5]. Non-biodegradable membranes, however, should be removed by an additional surgical operation, which may cause infection or inflammation of the operated site. For this reason, various biodegradable polymer membranes have been developed to eliminate the need of revision surgery. The most common biodegradable membranes are made of collagen materials of animal origin (collagen type I and III of porcine and bovine origin). Such barriers are currently the most frequently used and clinically relevant. Their main characteristics are a mild degradation profile and satisfactory tissue growth. Such membranes provide stable support, although sometimes there is a need to use stitching/ clamping pins to prevent from material movement in defect site. A disadvantage of such materials is the need of extraction from animal tissues and long painstaking process of material preparation including enzymatic cleaning, freeze-drying and sterilization. To eliminate the need of animal tissues, use, barrier membranes made of synthetic biodegradable polymers were recently developed. The most commonly used for this purpose are PLA, PLLA, PDLLA, PGA PLGA and PCL certified by FDA (Food and Drug Administration). From these materials' solid membranes or in the form of a fibrous meshes are produced by various methods. These ensure good maintenance on the defect and relative cell infiltration barrier. Synthetic polymer membrane degradation by-products are fully metabolized by the body. However, for synthetic biopolymers there is an increased risk of inflammation around the membrane resulting from a locally occurring decrease in $\mathrm{pH}$ in the tissues. Although currently reported membranes consist of the similar polymeric materials, the efficacy of GTR is quite different according to its structure and morphology. Novel experimental findings also suggest that membranes should play an active role in promoting the regenerative processes, instead of being purely a passive physical barrier. The optimization of membrane materials by systematically addressing both the barrier and the bioactive properties is an important strategy in biomaterials field of research. Next generation of the barrier membranes are composite materials developed with the addition of osteoinductive calcium phosphates, most preferably in nanoparticulate form. Such composites are intended to enhance active bone tissue regrowth due to application of ceramics with high chemical affinity to human bone. Tavakoli Darestani $\mathrm{R}$, recently reported successful production of PLGA/collagen and
Nano-hydroxyapatite material production [6]. Kikuchi et al. have shown $\beta$-tricalcium phosphate and poly (L-lactide-co-glycolide-co$\varepsilon$-caprolactone) composites to be promising constructs for the GTR procedures [7]. Liao et al. proposed functionally graded membrane composed of Nano-carbonated hydroxyapatite/collagen/PLGA to enhance the regeneration process [8]. Qiang et al. [9] and Rogowska-Tylman et al. proposed more recently, promising material compositions of fibrous base structure of PDLLA and PDLLA/PLGA respectively coated with Nano-hydroxyapatite particles [10].

\section{Conclusion}

Current trend is designing membranes with not only biodegradability or friendly support for the growth of cells but also additional functions, such as bone stimulating or antibacterial properties. In clinical practice, both and insoluble and biodegradable membranes are still used. Recent literature reports suggest more likely shift in the biodegradable instead of natural polymers compositions due to economical, ethical and religious implications.

\section{References}

1. J Gottlow, S Nyman, T Karring, Lindhe J (1984) New attachment formation as the result of controlled tissue regeneration. J Clin Periodontol 11(8): 494-503.

2. T Karring, S Nyman, J Gottlow, L Laurell (1993) Development of the biological concept of guided tissue regeneration-animal and human studies. Periodontology 2000 1: 26-35.

3. G Sam, BR Madhavan Pillai (2014) Evolution of barrier membranes in periodontal regeneration- "are the third-generation membranes really here? J Clin Diagnostic Res 8(12): ZE14-ZE17.

4. MC Bottino, V Thomas, G Schmidt, YK Vohra, TMG Chu, et al. (2012) Recent advances in the development of GTR/GBR membranes for periodontal regeneration - A materials perspective, Dent. Mater 28(7): 703-721.

5. YD Rakhmatia, Y Ayukawa, A Furuhashi, K Koyano (2013) Current barrier membranes: titanium mesh and other membranes for guided bone regeneration in dental applications. J Prosthodontic Res 57(1): 3-14.

6. Tavakoli Darestani R, Kazemian GH, Emami M, Kamrani Rad (2013) Poly (lactide-co-glycolide) nanofibers coated with collagen and nanohydroxyapatite for bone tissue engineering. Novelty in Biomed 1: 8-15.

7. M Kikuchi, Y Koyama, K Takakuda, H Miyairi, N Shirahama, et al. (2000) In-vitro change in mechanical strength of $\beta$-tricalcium phosphate/ copolymerized poly(L-lactide) composites and their application for guided bone regeneration. J Biomed Mater Res 62(2): 265-272.

8. S Liao, W Wang, M Uo, S Ohkawa, T Akasaka, et al. (2005) A three-layered Nano-carbonated hydroxyapatite/collagen/PLGA composite membrane for guided tissue regeneration. Biomaterials 26(36): 7564 -7571.

9. L Qiang, C Zhang, F Qu, X Wu, H Wang, et al. (2018) Electrospun Porous PDLLA Fiber Membrane Coated with nHA. Appl Sci 8(5): 831-844.

10.J Rogowska Tylman (2018) Polish Patent Application Biological Barrier Membrane. pp. 427554. 
ISSN: 2574-1241

DOI: 10.26717/BJSTR.2019.16.002807

Julia Higuchi. Biomed J Sci \& Tech Res

(C) This work is licensed under Creative

Submission Link: https://biomedres.us/submit-manuscript.php

$\begin{array}{ll}\text { BIOMEDICAL } & \text { Assets of Publishing with us } \\ \text { RESEARCHES } & \text { Global archiving of articles } \\ & \text { - Immediate, unrestricted online access } \\ \end{array}$

